\title{
Predicting Long-Term Developmental Outcomes From Maternal Perceptions of Infant and Toddler Behavior
}

\author{
SHERYL L. OLSON \\ University of Michigan \\ JOHN E. BATES AND KATHRYN BAYLES \\ Indiana University
}

\begin{abstract}
The purpose of this study was to examine the long-term developmental correlates of maternal perceptions of infant and toddler behavior. Maternal ratings of children's social behavior and developmental progress were obtained when the children were 13 and 24 months of age, using the Maternal Perceptions Questionnaire. These early perceptions measures were intercorrelated with follow-up measures of children's developmental competence and behavioral adjustment at age 6. Maternal evaluations of child characteristics in the 2 nd year predicted not only their own ratings of child behavioral adjustment but also teacher, examiner, and laboratory performance measures of cognitive competence and social adjustment. Although predictive correlations were generally modest, maternal perceptions scales showed meaningful patterns of relationships with later child characteristics, pointing to the desirability of further research on this topic.
\end{abstract}

behavioral adjustment maternal infant perceptions
longifudinal sample

During the last decade, there has been a surge of interest in parents' perceptions and interpretations of their children's behavior (Sigel, 1981). Parental cognitions have been acknowledged as important components of parent-child relationships (Bell, 1979). Parental cognitions may influence children's developmental outcomes through direct processes, such as disciplinary styles or teaching techniques, or indirectly through the manner in which the parent structures the child's physical and social environment. Moreover, indexes of parental cognition have gained acceptance as important tools for assessing children's behav-

This research was supported by NIMH grants MH28018 to J.E. Bates and MH38605 to S.L. Olson. The authors thank the families who participated and others whose help was essential in data collection: Beth Ridge, Melinda Monroe, and Jeff Harness.

Correspondence and requests for reprints should be sent to S.L. Olson, Department of Psychology, University of Michigan, 580 Union Drive, Ann Arbor, MI 48109-1346. 
ioral adaptation and developmental status (Maccoby \& Martin, 1983). For example, the most widely used methods of assessing early temperamental style and psychopathology are based on parental report questionnaires. Partial support for the validity of parent reports comes from studies showing modest levels of convergence between parental assessments of children's behavior and concurrent "objective" measures (e.g., Bates \& Bayles, 1984).

Finally, in a related application, parental perceptions of children's behavior may be clinically useful as early screening measures. In order to support this notion, the long-term predictive validity of parental perceptions as "risk indicators" must be documented. Previous research on this question has been sparse and inconsistent. Broussard and Hartner (1971) reported that 1-month-old firstborns rated by their mothers as "average" or "worse than average" on variables such as crying and sleeping were at elevated risk for poor socioemotional functioning at ages 4 to 5 . Mothers who perceived their infants as "better than average" ( $61 \%$ of the sample) also reported experiencing less depression, irritability, and physical illness than other mothers. Considering the extreme shortness of the rating scale (six items), the predictive power was impressive. However, its interpretation was left unclear; Broussard and Hartner questioned whether the long-term relationship between maternal perceptions and later child functioning reflected consistent problems in dyadic adjustment, or merely consistent subjective distortion in maternal reports.

Palisin (1980) attempted to replicate Broussard and Hartner's findings, without success. Palisin's subjects differed from those of Broussard and Hartner in several ways, including geographic locale, sex distribution of children in the follow-up groups, and age of children at follow-up. Even so, her findings do raise questions about maternal perceptions of early infant behavior as predictors of children's long-term developmental outcomes.

However, other studies are more supportive of the predictiveness of early mother perceptions. Bates, Maslin, and Frankel (1985) reported that maternal perceptions of infant temperament and developmental functioning predicted maternal reports of problem behavior at age 3. Bates and Bayles (1987) obtained similar results in follow-ups at ages 5 and 6 . It was argued that predictive relationships between parent perceptions and children's later behavior problems did not solely reflect consistency in a global positive-negative bias in maternal reporting: There were meaningful qualitative relationships between different types of predictor and outcome variables. For example, maternal perceptions of infants' fearful reactions to novelty predicted later anxiety problem scores, whereas perceptions of early resistance to control predicted later "externalizing" problems such as hyperactivity and aggression. Furthermore, Bates and Bayles (1984) showed that although their maternal perceptions variables possessed both "subjective" (e.g., personality) and "objective" (keyed to overt child characteristics) sources of variance, they were low in overlap with indices of general response bias. 
Other recent investigators have also found consistent relationships between temperamental indexes in infancy/toddlerhood and later parent reports of behavior problems (Guerin \& Gottfried, 1986; Kohnstamm, 1984; Swets-Gronert, 1984; Wolkind \& De Salis, 1982). Additionally, outcome measures other than parent reports have been used in a few studies. Guerin and Gottfried (1986) found that early difficultness predicted teacher reports of behavior problems in girls, but the correlation did not reach significance for boys, although it was in the same direction as that for girls. Bates et al. (1985) found that babysitters', preschool teachers', and other secondary caregivers' ratings of 3-year-olds' behavior problems were not significantly predicted by mother reports of difficultness in infancy. However, hostile problem ratings by the secondary caregivers were predicted by a combination of mother scales during infancy: Infants were seen as responding negatively to change in general but, at the same time, were extraverted with people. Finally, Carey, Fox, and McDevitt (1977) found that parent perceptions of infant difficultness at age 6 months were predictive of school-age reflectivity-impulsivity and teacher-rated behavioral adjustment. These predictive correlations were modest in degree and curvilinear: Infants rated extremely "easy" in temperamental style were just as likely as those rated extremely "difficult" to manifest later adaptive problems. Although the curvilinear pattern was counterintuitive, it is conceivable that "easy" temperament ratings may have reflected withdrawn, unresponsive social behavior in some infants.

In summary, research on the predictive validity of maternal perceptions measures has been encouraging but not entirely consistent nor powerful. Further research is needed to help us draw more precise generalizations.

The purpose of the present study was to provide further empirical examination of the long-term correlates of maternal perceptions measures. In previous studies, maternal perceptions of a broad range of child behaviors were assessed (longitudinally) at ages 13 and 24 months, using the Maternal Perceptions Questionnaire (MPQ; Olson, Bates, \& Bayles, 1982). The MPQ was designed to assess developmentally relevant behavioral characteristics in the 2nd year, including facility of speech and language acquisition, sociability to strangers, social responsiveness to mother, and resistance to discipline. The broad developmental scope of the questionnaire differentiates it from infant temperament questionnaires, which focus more narrowly on infant fussiness and related temperamental constructs. Early studies focused on examining the psychometric properties of the MPQ. Three different dimensions of behavior, common to both age points, were extracted from factor analyses of items: Language Competence, the mother's perception of the child's developing facility with speech and language skills; Unsociability, the mother's perception of the child's shyness in the presence of strangers; and Unresponsiveness, an index of the mother's perception of the attachment relationship, particularly her feeling of emotional rejection by her infant (e.g., "I wish baby were more affectionate to 
me;" "baby would rather play by self than with me;" "baby isn't glad to see me"). Despite differences in the number and content of items at each age point, corresponding factor scales had moderately high stability between 13 and 24 months (range $=.45-.60$ ). At 24 months, a fourth robust dimension emerged (Troublesome), which indexed maternal perceptions of child resistance to discipline.

Subsequently, we examined the generalizability of these measures to "objective" assessments of early developmental competence and the mother-child relationship. The MPQ Language Competence scale showed the strongest pattern of convergence with external measures, especially at the 24 -month level. For example, maternal perceptions of language competence correlated robustly ( $r$ ranged from .50 to .70 ) with test and observation measures of children's cognitive and linguistic maturity, and with frequency of mother-child verbal interaction in the home. The MPQ Unsociability dimension also showed a meaningful pattern of convergence with external measures, such as examiners' ratings of child sociability in a laboratory testing situation. Furthermore, the MPQ Troublesome scale correlated significantly (albeit modestly) with the frequency of conflict-oriented mother-child interactions observed in the home. However, Unresponsiveness to Mother, the most inherently "subjective" rating dimension, showed few relevant convergences with measures of social interaction and child competence.

Having documented some meaningful objective correlates, we examined maternal perceptions measures in light of general background features, such as family occupational level, child gender, and birth order, and subjective components, such as maternal personality characteristics or response biases (Bates \& Bayles, 1984). Generally, background features were uncorrelated with the maternal perceptions scales. However, social desirability made significant but not large contributions to mothers' evaluations of language competence and unsociability, whereas maternal anxiety problems predicted the Troublesome and Unresponsiveness scales (Bates \& Bayles, 1984).

Finally, our prior attempts to document the long-term predictive validity of the maternal perceptions scales have been encouraging (see Bates et al., 1985) but were limited to maternal reports of problem behavior as "outcome" variables. In order to make a more convincing case for the predictive value of early maternal perceptions measures, we needed to show that they predicted a broad range of relevant developmental criteria independent of maternal report. This was the primary purpose of the present study.

Follow-up assessments were carried out when the children were 6 years old, and focused on the following developmental constructs: (a) cognitive and linguistic competence, defined by scores on laboratory tests of vocabulary competence and cognitive control over behavior, as well as mother and teacher ratings of academic competence; (b) social competence/sociability, defined by a test of interpersonal problem-solving ability, examiners' ratings of sociability, 
and mother and teacher ratings of social competence; and (c) behavioral adjustment, defined by mother and teacher responses to standardized child behavior-problem checklists.

Our main research goal was to determine whether maternal perceptions of childrens' early behavioral characteristics predicted relevant measures of social and cognitive functioning over a long time span. On the basis of previous research, we expected that the Language Competence scale would predict later vocabulary competence, and other cognitive-relevant outcomes such as levels of impulse control and academic competence. We also expected that maternal perceptions of early externalizing-type behavior problems might predict later impulsivity and academic problems. Because the Troublesome scale has been related to maternal behavior problem reports at earlier age levels, we expected that this pattern would persist to the 6-year level. Although we have never before predicted teacher's behavior problem ratings, the Troublesome scale would be the strongest expected antecedent on the basis of content similarity. It is also conceivable that maternal perceptions of unsociability might predict some internalizing-type problem behaviors such as social withdrawal/anxiety, and that the Unresponsiveness scale, which indexes maternal perceptions of the attachment relationship, might predict general behavioral maladjustment. Finally, we expected (on the basis of content similarity) that maternal perceptions of early child sociability would be the most consistent predictors of later social competence and sociability.

\section{METHOD}

\section{Subjects}

Subjects were part of an ongoing longitudinal study of parent-infant relationships and their long-term developmental sequelae. Families were originally recruited, using local birth announcements, when the infants were between 5 and 6 months of age (see Bates, Olson, Pettit, \& Bayles, 1982, for details). The sample was $52 \%$ male and $48 \%$ firstborn. Family occupation levels, rated according to the higher status of either parents' job, were $14 \%$ upper-middle, $70 \%$ middle, and $16 \%$ lower-middle class. Nearly all of the mothers were white $(98.9 \%)$ and averaged 25 years of age. At the time of recruitment, there were 168 parent-infant dyads. Follow-up assessments were conducted when the children were 13 months $(N=134), 24$ months $(N=120)$, and 6 years $(N=80)$ of age. Subject attrition was mostly due to familial relocation and was not selective on the basis of major sample characteristics. Parents were paid for their participation at each assessment point.

\section{Maternal Perception Measures in the 2nd Year}

Mothers completed the Maternal Perceptions Questionnaire (MPQ; Olson et al., 1982) when their infants were 13 and 24 months of age. The MPQ consists 
of a series of 7-point scales (26 at 13 months and 39 at 24 months) on which parents rate aspects of their children's social and intellectual behavior. Common factors at both age levels include Language Competence, Unresponsiveness to Mother, and Unsociable to Strangers. Other scales include: Psychomotor Incompetence (13 months), Compliant and Mature ( 24 months), and Troublesome to Discipline (24 months). Item constituents of each factor scale are listed in Appendix A. For detailed information concerning the psychometric features of the questionnaire, see Olson et al. (1982).

\section{Follow-Up Measures at Age 6}

Follow-up assessments of social and cognitive competence were carried out when the children were 6 years old, using multiple measures and informants. Performance measures of impulse control, social problem-solving ability, and vocabulary competence were administered in the laboratory. These measures were supplemented by examiner ratings of sociability in the lab setting and by parent and teacher ratings of behavioral adjustment and social competence in the home and school settings. Children visited the laboratory on 2 separate days, scheduled approximately 1 week apart.

Measures of Impulsivity. Children participated in a series of laboratory tasks, each designed to measure a major operational definition of impulse control. Descriptions of each task are as follows:

1. Matching Familiar Figures Test (MFFT): a measure of cognitive impulsivity developed by Kagan, Rosman, Day, Albert, and Phillips (1964) and used extensively by researchers to assess childhood self-control. A single drawing of a familiar object, the standard stimulus, is paired with an array of six variants of the drawing. All but one of the variants differ slightly from the standard stimulus, and the child must choose the alternative that matches the standard stimulus exactly. Dependent variables are latency to first response and number of errors.

2. Draw-a-Line-Slowly, Walk-a-Line-Slowly: measures of the ability to inhibit fine and gross motor movements in response to situational demands (Maccoby, Dowley, Hagen, \& Degerman, 1965). The following version of the test was adapted by Arend, Gove, and Sroufe (1979). Draw-a-lineslowly: Each child is given an 8 " $\times 11$ " piece of paper with two "telephone poles" drawn in black ink. The child is given practice using a ruler, then asked to connect the poles by drawing a straight line. After two trials at regular speed, the child is asked to draw the line as slowly as possible (two trials). Walk-a-line-slowly: The child is asked to walk a 6-foot-long "sidewalk" (marked with tape on the floor) at regular speed (two trials) and then as slowly as possible (two trials). Both tasks yield regular speed and inhibition (average regular minus average slow trials) scores. 
3. Delay of Gratification: a measure of self-control developed by Arend et al. (1979). In this task, the examiner "discovers" a small wrapped gift and informs the child that s/he may have it "later." A 2- to 3-min cuver task is then carried out, during which the experimenter records any attempts to open the gift prematurely. Dependent variables include: number of times the child touches the gift, number of verbal references to the gift, and amount of time that elapses before child takes the gift.

4. Choice Delay: a test of the ability to delay immediate gratification for a larger outcome (Mishel, 1958). On the first testing day, the child is offered a choice between a small treat immediately available or a larger treat available the next day. On the second testing day, the child is asked to choose between a single treat immediately or a handful of treats later on.

In order to reduce the performance measures of self-control into a more manageable subset of composite variables, principal-components analyses were carried out (Olson, Bates, \& Bayles, 1987). The following variables were entered into the analysis: Matching Familiar Figures Test reaction time and error scores; verbal references to the gift, frequency of gift touching, and response time on the delay of gratification task; choice delay score (immediate vs. delayed); average walking speed, regular trials, average drawing speed, regular trials, and inhibition scores (average regular minus average slow trials, walking and drawing). The principal-components analysis resulted in two orthogonal dimensions of self-control. One factor, labelled Inhibitory Control, was defined by the MFFT reaction time score and motor inhibition scores for the drawing and walking tasks, with a negative loading for the MFFT error score. Thus, this dimension represents degree of cognitive control over behavior in highly structured task situations. The second factor dimension was defined by the three delay-of-gratification test variables, with negative loadings for number of verbal references to the gift and frequency of gift touching, and a positive loading for the amount of time elapsed before the child took the gift. This dimension indexes the child's ability to delay immediate personal gratification in a task situation. Unweighted composite scores were constructed for each factor dimension. In addition, the choice delay score was retained as an individual variable, because it did not load significantly on either factor and was of interest in its own right.

Social Problem-Solving. The Preschool Interpersonal Problem-Solving Test (PIPS; Shure \& Spivack, 1974) was individually administered to each child during a laboratory session. In the PIPS task, children are presented with a series of hypothetical conflict situations involving same-sex peers, and children and their mothers. Subjects are asked to provide as many different solutions as possible to each type of conflict situation. Dependent measures include number 
of different, task-relevant solutions and proportion of forceful-aggressive solutions.

Vocabulary Test. The Peabody Picture Vocabulary Test-Revised (Dunn \& Dunn, 1981), a short test of receptive vocabulary, was administered to each child in the laboratory.

Examiner Ratings. Subsequent to laboratory testing, examiners rated each child's performance and demeanor on 5-point scales. Interrater reliability, computed using Pearson correlation, averaged $.81(n=42$; range $=.78-.85)$. The Extraversion versus Social Withdrawal/Fearfulness scale was extracted for use in the current study.

Parent and Teacher Questionnaires. Mothers completed the Child Behavior Checklist (CBCL; Achenbach, 1978), which is a well-standardized measure of childhood psychopathology with high (greater than .90 ) test-retest reliability for all scales (Achenbach \& Edelbrock, 1978). The CBCL consists of 118 items that are scored 0,1 , or 2 representing, respectively, "not true," "somewhat true," or "very true" with respect to the child. Twenty additional items were designed to assess the child's social and cognitive competence at home and at school. The behavior problem subscales of the CBCL are summarized according to two global dimensions: Externalizing Problems (fighting, noncompliance, negativism, impulsivity, etc.) and Internalizing Problems (anxiety, social withdrawal, poor self-concept, etc.). The 20 competence items were summarized according to the following competence domains: (a) Activities, an index of the amount of time the child spends on sports, hobbies, and household chores, along with ratings of the child's competence in each area; (b) Social, an index of the child's competence with peers, siblings, and parents, as well as the amount of time spent in clubs and with friends; and (c) Academic, an index of the child's competence in academic subjects minus academic problems.

Teachers filled out the teacher-appropriate version of the Achenbach CBCL. The child's academic competence was also rated (on a 5-point scale ranging from "far below grade" to "far above grade"). Finally, the Teacher's Checklist of Children's Peer Relationships (Dodge, 1983) was also completed to provide additional information concerning social competence. This is a short (18-item) questionnaire consisting of three 5-point scales: peer acceptance versus isolation or rejection (6 items), aggression versus social cooperativeness ( 5 items), and social skillfulness, defined as understanding others' feelings, accurately interpreting the intentions of peers, and using good social problemsolving skills (7 items). Despite repeated attempts to collect questionnaires from all teachers, only 45 complete data sets were obtained.

Intercorrelations between mothers and teachers on common scales are contained in Appendix B. Generally, there were modest levels of agreement between the two informants. 
TABLE 1

MPQ Correlates of Behovioral Adjustment at Age 6

\begin{tabular}{|c|c|c|c|c|}
\hline & \multicolumn{2}{|c|}{ Maternal Achenbach } & \multicolumn{2}{|c|}{ Teacher Achenbach } \\
\hline & Internalizing & Externalizing & Internalizing & Externalizing \\
\hline \multicolumn{5}{|l|}{ 13-Month MPQ } \\
\hline Language Competence & .07 & -.11 & .17 & $-.30^{*}$ \\
\hline Unresponsiveness & .05 & .19 & .07 & $.32^{*}$ \\
\hline Unsociability & .10 & .11 & .01 & -.02 \\
\hline \multicolumn{5}{|l|}{ 24-Month MPQ } \\
\hline Language Competence & -.06 & .19 & .06 & .02 \\
\hline Troublesome & $.42^{* * \hbar}$ & $.59 * * *$ & $.30^{*}$ & .29 \\
\hline Unresponsiveness & $.25^{*}$ & $.38^{\star \star}$ & $.34^{*}$ & .28 \\
\hline Unsociability & .18 & $-.26^{*}$ & $.33^{*}$ & .20 \\
\hline
\end{tabular}

\section{RESULTS}

Maternal Perceptions Questionnaire scales were intercorrelated with follow-up measures, which we clustered into three broad domains of child functioning: behavioral adjustment, cognitive competence, and social competence. We emphasized as predictors the 24-month versions of the four main MPQ factor scales, although correlations with complementary 13-month MPQ scales were also computed. Intercorrelations between two minor age-specific scales and children's age-6 functioning are described below in a footnote. ${ }^{\prime}$

\section{Prediction of Behavioral Adjustment Ratings}

Maternal Perceptions Questionnaire correlates of mother and teacher behavior problem ratings are shown in Table 1 . As expected, the most striking predictions were from the MPQ Troublesome scale to mothers' ratings of externalizing problems. This pattern indicates direct predictive continuity in maternal perceptions, because Troublesome pertains to externalizing-type behavior in the toddlers. Early Troublesome scores also predicted the 6-year Achenbach Internalizing Problems scale, suggesting that early maternal perceptions of problem behavior are predictive of a wide range of later adjustment difficulties, not just

\footnotetext{
' Correlations between two short age-specific scales and age-6 follow-up measures were also computed to provide a complete picture of the long-term correlates of the MPQ measures. The 13-month MPQ scale Psychomotor Incompetence (see Appendix A for item content) correlated negatively with mothers' later ratings of competence in extracurricular activities $(r=-.36, p<.01)$ and in school subjects $(r=-.30, p<.01)$. Psychomotor Incompetence also predicted impulsive responding on the laboratory index Inhibitory Control $(r=-.23, p<.05)$ and correlated positively with preferences for aggressive solutions to social problem situations on the PIPS test $(r=.23$, $p<.05$ ). Consistent with the pattern of low external validity reported in Olson et al. (1982), the 24-month scale Compliant and Mature had no significant age-6 correlates.
} 
conduct problems. Perhaps most importantly, Troublesome scores predicted teacher ratings of internalizing problem behavior, demonstrating that the relationship between mother perceptions and later child adjustment extends to outcome measures that are independent of maternal report. A similar predictive pattern was found for the 24-month Unresponsiveness to Mother scale. Highly unresponsive toddlers tended to be seen by mothers and by teachers as having more behavior problems at age 6 .

Finally, we expected that the MPQ Unsociability scales would predict later internalizing problems to a modest degree. Unsociability at 24 months predicted teacher perceptions of internalizing problems, and it did not predict externalizing problems significantly. However, a different pattern was obtained for the maternal ratings. Unsociability did not significantly predict internalizing problems but was negatively predictive of later externalizing problems. The latter pattern is consistent with the concepts underlying the scales, in that a child with longstanding shyness would have less inclination to act aggressively.

\section{Prediction of Cognitive-Relevant Outcomes}

Intercorrelations between MPQ scales and measures of children's cognitive and academic competence yielded some expected predictive patterns. As shown in Table 2, the 24-month Language Competence scale did predict children's vocabulary competence, as expected. This scale also predicted the tendency of the child to choose a larger, but delayed, treat. However, contrary to expectation, Language Competence did not predict other measures of impulsivity or adult ratings of academic competence.

A second mother perception scale, Unsociability, was also predictive of later cognitive performance. At 13 months, Unsociability predicted lower vocabulary scores. However, this relationship did not persist to the 24-month level, indicating that unsociability is an unreliable correlate of later cognitive test performance.

Finally, although Troublesome failed to predict later impulsivity, mothers' ratings of academic competence were modestly negatively predicted by this scale. However, teachers' ratings of academic competence were independent of all MPQ scales.

\section{Prediction of Social Competence/Sociability}

Measures of social competence included scores on a test of social problemsolving ability, examiners' ratings of sociability, and mother and teacher ratings of social competence with peers and adults. As expected, the MPQ Unsociability scale was the most consistent predictor of children's later sociability and social competence (see Table 3 ). Unsociability at both age levels was negatively correlated with social problem-solving ability on the PIPS test and with examiners' ratings of sociability during laboratory testing. The 24-month Unsociability scale also predicted teachers' ratings of social skillfulness but was uncorrelated with maternal ratings of social competence. 


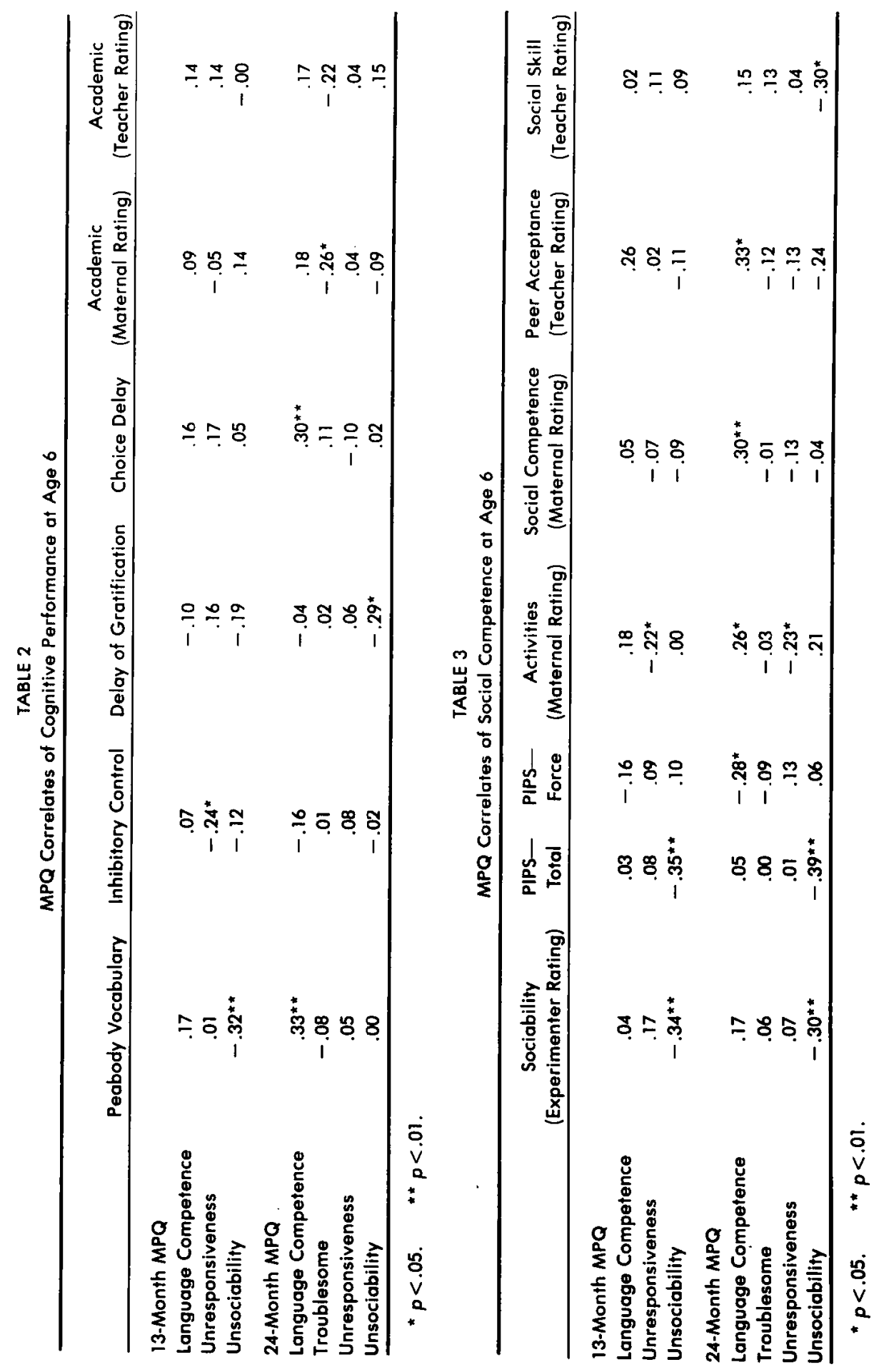


Although we did not predict this pattern, the other consistent correlate of later social competence was perceived Language Competence. The 24-month Language Competence scale predicted mothers' ratings of social competence on the Achenbach and teachers' ratings of positive peer acceptance on the Dodge Questionnaire. Finally, 24-month Language Competence also predicted the proportion of PIPS social problem solutions that were nonaggressive.

\section{DISCUSSION}

There have been demonstrations previously that mothers' perceptions of their infants predict, in coherent fashion, their ratings of child behavioral adjustment some years later. However, there have been very few, and inconsistent, prior demonstrations that mothers' perceptions of their infants can predict, 4 to 5 years later, indexes of child adjustment outside of the relationship with the mother. In the absence of convincing demonstrations, one would naturally wonder if the predictiveness of mother ratings of infants represents only consistency in the mother's way of perceiving the child, rather than continuity in more generalizable characteristics of the child.

We have not been inclined to accept this interpretation. We saw nothing in the prior data to suggest that the cross-time links reflect a simple, general positivity-negativity bias in mothers' perceptions; in fact, various dimensions of child characteristics have been consistently well-differentiated across development by mothers, for example, early anxiety analogs predicting better to later anxiety than to externalizing behaviors, and vice versa (Bates \& Bayles, 1984). Furthermore, we had objectively observed conflicted mother-child interactions at 24 months (Lee \& Bates, 1985) and 4 years (Pettit \& Bates, 1984) consistent with mother reports of difficult versus easy temperament in infancy. However, we still lacked assurance that early mother reports predicted relevant child outcomes assessed independently of the mother.

The current findings show that early mother reports of problems in the mother-toddler relationship predicted later adjustment problems not only from the mother's perspective but also from the teacher's. At its negative pole, the Troublesome scale describes children perceived as frequently angry, defiant, and limits-testing vis-a-vis the mother. Based on previous research, we expected this scale to predict age 6-year maternal reports of problem behavior (particularly "externalizing" problems). The finding that Troublesome also predicted teacher reports of behavioral maladjustment supports the generalizability of early maternal evaluations to other settings and informants.

There was also a modest but consistent relationship between early maternal perceptions of child unresponsiveness and later reports of child maladjustment. Once again, this relationship characterized both mother and teacher follow-up reports. The central feature of the Unresponsiveness scale is the mother's subjective feeling of rejection by her child. The content of the scale, combined 
with long-term predictions to later behavioral deviance, suggests that some mothers who have difficulty managing their toddlers may tend to personalize difficult, noncompliant child behavior. If this is indeed the case, then the role of mothers' early causal attributions in the long-term perpetuation of motherchild relationship problems is worthy of further study.

As expected, maternal perceptions of language competence at age 2 did predict children's vocabulary competence at age 6 , supporting the predictive validity of the rating dimension to directly related measures of child competence. However, contrary to expectation, Language Competence did not predict ratings of academic competence. Furthermore, given the critical importance of cognitive/ linguistic skills to children's developing impulse control capabilities (e.g., Kopp, 1982), we expected that evaluations of language competence might predict later measures of impulsivity. However, language competence predicted only one measure of impulse control-willingness to wait for a larger prize instead of taking a small one immediately.

Although we did not expect this predictive pattern, high language competence ratings at age 2 were associated with high social competence ratings at age 6 , on behalf of both teachers and mothers. This pattern is not entirely surprising, because verbal communicative competence is thought to play an important role in children's developing social competence (e.g., Hops, 1983).

Finally, mothers' perceptions of early child unsociability were the most consistent correlates of children's later social competence. For example, early unsociability forecasted poor performance on a test of social problem-solving, examiner ratings of unsociability, and teacher reports of poor social skills with peers. These predictive linkages did not extend to mothers' ratings of social competence, perhaps because the maternal scale primarily indexed positive intrafamilial relationships, rather than sociability with strangers.

In conclusion, although predictive correlations were modest, the present findings extend our previous work by showing that maternal evaluations of early child characteristics were predictive of a broad range of later child outcomes. Predictive relationships generally spanned different settings and informants and tended on the whole to be conceptually coherent.

How do the broadly focused MPQ scales compare, as long-term predictors, with different scales, such as those assessing mother's perceptions of infant temperament? In other research we have found that temperamental difficultness (on the Infant Characteristics Questionnaire) was primarily correlated with maternal behavior problem ratings at age 6, and not with teacher, examiner, and performance measures of children's social and cognitive competence (Olson, Bates, \& Bayles, 1986). Thus, perceived temperamental difficultness mostly relates to rated behavioral deviance at age 6 , whereas the broader MPQ scales correlate with a more diverse range of outcome variables. These combined data provide further evidence for the idea that mothers can evaluate their infants' characteristics in a fairly differentiated way. 
Further research might build on the current findings in two directions. First, the predictive properties of the MPQ could be examined in greater detail. For example, studies might be directed at the question of what factors moderate the predictiveness of the MPQ scales, such as continuity versus disruption in family circumstances or mother causal attributions about the child behavior being described. The second research direction is to construct new scales, perhaps along the model of the MPQ, which assess concepts theoretically and empirically related to important developmental outcomes. For example, perhaps the Troublesome and Unresponsiveness scales could be psychometrically improved by the addition of further items and, thus, be made a stronger predictor of later adjustment. In any event, the current study has been useful in demonstrating the predictive value of early maternal perceptions, pointing to the desirability of further research on this topic.

\section{REFERENCES}

Achenbach, T.M. (1978). The Child Behavior Profile. Journal of Consulting and Clinical Psy. chology, 46, 478-488.

Achenbach, T.M., \& Edelbrock, C.S. (1978). The classification of child psychopathology: A review and analysis of empirical efforts. Psychological Bulletin, 85, 1275-1301.

Arend, R., Gove, F.C., \& Sroufe, L.A. (1979). Continuity of individual adaptation from infancy to kindergarten: A predictive study of ego-resiliency and curiosity in preschoolers. Child Development, 50, 950-959.

Bates, J.E., \& Bayles, K. (1984). Objective and subjective components in mothers' perceptions of their children from age 6 months to 3 years. Merrill-Palmer Quarterly, 30, 111-130.

Bates, J.E., \& Bayles, K. (1987). The role of attachment in the development of behavior problems. In J. Belsky \& T. Nezworski (Eds.), Clinical implications of attachment. Hillsdale, NJ: Erlbaum.

Bates, J.E., Maslin, C.A., \& Frankel, K.A. (1985). Attachment security, mother-child interaction, and temperament as predictors of behavior problem ratings at three years. In I. Bretherton \& E. Walters (Eds.), Growing points of attachment theory and research (Special Issue). Monographs of the Society for Research in Child Development, 50, (No. 209).

Bates, J.E., Olson, S.L., Pettit, G.S., \& Bayles, K. (1982). Dimensions of individuality in the mother-infant relationship at six months of age. Child Development, 53, 446-461.

Bell, R.Q. (1979). Parent, child, and reciprocal influences. American Psychologist, 34, 821-826.

Broussard, E.R., \& Hartner, H.S.S. (1971). Further considerations regarding maternal perception of the firstborn. In J. Hellmuth (Ed.), Exceptional infant: Studies in abnormality (Vol. 2). New York: Brunner/Mazel.

Carey, W.B., Fox, M., \& McDevitt, S.C. (1977). Temperament as a factor in early school adjustment. Pediatrics, 60, 621-624.

Dodge, K.A. (1983). Teacher's Checklist for Children's Peer Relationships. Department of Psychology, Indiana University, Bloomington.

Dunn, L.M., \& Dunn, L. (1981). Peabody Picture Vocabulary Test-Revised. Circle Pines, MN: American Guidance Service.

Guerin, D., \& Gottfried, A.W. (1986, April). Infant temperament as a predictor of preschool behavior problems. Poster presentation, International Conference on Infant Studies, Los Angeles, CA.

Hops, H. (1983). Children's social competence and skill: Current research practices and future directions. Behavior Therapy, 14, 3-18. 
Kagan, J., Rosman, B.L., Day, D., Albert, J., \& Phillips, W. (1964). Information processing in the child: Significance of analytic and reflective attitudes. Psychological Monographs, $78(1)$.

Kohnstamm, G.A. (1984, April). Bates' Infant Characteristic's Questionnaire (ICQJ in the Netherlands. Paper presented at the International Conference on Infant Studies, New York.

Kopp, C.B. (1982). The antecedents of self-regulation: A developmental perspective. Developmental Psychology, 18, 199-214.

Lee, C.L., \& Bates, J.E. (1985). Mother-child interaction at age two years and perceived difficult temperament. Child Development, 56, 1314-1325.

Maccoby, E., Dowley, E., Hagen, J., \& Degerman, R. (1965). Activity level and intellectual functioning in normal preschool children. Child Development, 36, 761-770.

Maccoby, E.E., \& Martin, J. (1983). Socialization in the context of the family: Parent-child interaction. In E.M. Hetherington (Ed.), Handbook of child psychology: Vol. 4, Socialization, personality, and social development. New York: Wiley.

Mishel, W. (1958). Preference for delayed reinforcement: An experimental study of a cultural observation. Journal of Abnormal and Social Psychology, 56, 57-61.

Olson, S.L., Bates, J.E., \& Bayles, K. (1982). Maternal perceptions of infant and toddler behavior: A longitudinal, construct validation study. Infant Behavior and Development, 5, 397-410.

Olson, S.L., Bates, J.E., \& Bayles, K. (1986, April). Predicting social and cognitive competence at age six. Early Mother-Child Interactions. Paper presented at the International Conference on Infant Studies, Los Angeles.

Olson, S.L., Bates, J.E., \& Bayles, K. (1987, April). Early social experience and the development of self-control. Paper presented at the biennial meeting of the Society for Research in Child Development, Baltimore, MD.

Palisin, H. (1980). The Neonatal Perception Inventory: Failure to replicate. Child Development, $51,737-743$.

Pettit, G.S., \& Bates, J.E. (1984). Continuity of individual differences in the mother-infant relationship from six to thirteen months. Child Development, 55, 729-739.

Sigel, I.E. (1981). Child development research in learning and cognition in the 80s: Continuities and discontinuities from the 1970s. Merrill-Palmer Quarterly, 27, 347-371.

Shure, M.B., \& Spivack, G. (1974). Preschool Interpersonal Problem-Solving Test Manual. Philadelphia: Hahneman Medical School and Hospital.

Swets-Gronert, F. (1984, August). Temperament in young children. Paper presented at the European Conference on Developmental Psychology, Groningen, The Netherlands.

Wolkind, S.N., \& De Salis, W. (1982). Infant temperament, maternal mental state, and child behavior problems. In R. Porter \& G.M. Collins (Eds.), Ciba Symposium \#89: Temperament differences in young children. London: Pitman.

25 September 1987; Revised 22 November 1988

\section{APPENDIX A}

\section{Item Constituents of MPQ Scales}

\section{3-Month Scales}

1. Unsociability (fuss when others pick up, shy and fearful-goes to new people, seems to enjoy people).

2. Unresponsive to mother (doesn't come to me enough, I wish baby were more affectionate to me, I find it hard to get baby's attention, baby would rather play by self than with me-glad to see me, listens when I speak, seems to understand me). 
3. Language Competence (picks up new words easily, says words back to me-I worry about ability to speak).

4. Psychomotor Competence (good sense of balance-clumsy movements, I worry about ability to learn).

\section{4-Month Scales}

1. Language Competence (picks up new words easily, fun to talk with, speaks in full sentences, understands more words than most age-mates, bright for age, easy to teach-I worry about ability to speak, hard to understand child's speech).

2. Troublesome (gets angry at me frequently, defiant and hard to control, always getting into trouble, frequent conflicts with other children).

3. Compliant and Mature (does what I ask, able to do things by self, excited by new toys, smiles when I approach).

4. Unresponsive to Mother (doesn't come to me enough, hard to get attention, I wish child were more affectionate to me-listens when I speak).

5. Unsociability (upset when left with sitter, shy and fearful-goes to new people).

\section{APPENDIX B}

Agreement Between Mothers and Teachers on Common 6-Year Scales'

\begin{tabular}{lccccc}
\hline & \multicolumn{5}{c}{ Teacher Scales } \\
Mother Scales & Academic & Internalizing & Externalizing & Peer & Social Skills \\
\hline Academic & .24 & .15 & .26 & -.22 & .08 \\
Internalizing & -.12 & $.36^{*}$ & .03 & -.28 & .00 \\
Externalizing & -.08 & .11 & .06 & -.04 & -.07 \\
Activities & .09 & $-.43^{\star *}$ & -.33 & $.29^{*}$ & $.35^{*}$ \\
Social Competence & .18 & $-.32^{*}$ & -.15 & .13 & .23 \\
\hline
\end{tabular}

'Ns ranged from 38-43.

$* p<.05$. ** $p<.01$. 